\title{
ОБЗОРЫ
}

УДК 62-1:62-5:62-9:629.33

\author{
НАУЧНЫЙ ОБЗОР РАЗРАБОТОК В ОБЛАСТИ СРЕДСТВ \\ ПРИНУДИТЕЛЬНОЙ ОСТАНОВКИ ТРАНСПОРТНЫХ СРЕДСТВ \\ ${ }^{1}$ Литвинов А.В., ${ }^{1}$ Князев К.С., ${ }^{1}$ Личман А.В., ${ }^{1}$ Колобашкин А.В., \\ ${ }^{1}$ Корыц С.И., ${ }^{1}$ Бокова И.Б., ${ }^{2}$ Чичин С.В. \\ ${ }^{\prime}$ ФГКОУ ВО Омская академия МВД России, Омск, е-таil: ота@тvd.ru; \\ ${ }^{2}$ Филиал ФГКВОУ ВО ВА МТО им. Генерала армии А.В. Хрулева, Омск, е-таil: otiu@mil.ru
}

\begin{abstract}
Статья посвящена обзору разработок в области средств принудительной остановки транспорта. Актуальность темы обусловлена повышенной степенью опасности, создаваемой в процессе преследования транспортного средства правонарушителя. Среди большого разнообразия применяемых способов остановки транспортных средств все же имеются ряд недостатков, которые отражаются на эффективности процесса остановки. Некоторые из применяемых средств принудительной остановки транспорта, состоящие на вооружении в органах Внутренних дел, морально и физически устарели, что, безусловно, требует особого внимания и подхода к указанной проблеме. На основании проведенного обзора предложена классификация средств принудительной остановки транспорта по видам базирования, типу применяемых устройств, характеру и способам воздействия на останавливаемое транспортное средство. Авторами отмечается, что, помимо состоящих на вооружении органов внутренних дел Российской Федерации средств принудительной остановки транспорта, принцип работы которых основан на прокалывании шин преследуемых транспортных средств, существует достаточно большой объем устройств, основанных на новых принципах. Рассмотренные в научном обзоре разработки могут дополнить функциональные особенности существующих, повышая в целом эффективность процесса остановки транспортного средства правонарушителя, и заменить их, представляя достойную альтернативу. В результате исследования авторами внесены предложения по повышению эффективности применения средств принудительной остановки транспорта, по комплектованию территориальных органов внутренних дел соответствующими устройствами, осуществлению контроля и диагностики качества производства и использования указанных средств.
\end{abstract}

Ключевые слова: научный обзор, принудительная остановка, средства принудительной остановки транспорта, классификация, предложения, повышения эффективности, контроль

\section{SCIENTIFIC REVIEW OF DEVELOPMENTS IN THE FIELD OF MEANS OF FORCED STOPPING OF VEHICLES}

\author{
${ }^{1}$ Litvinov A.V., ${ }^{1}$ Knyazev K.S., ${ }^{1}$ Lichman A.V., ${ }^{1}$ Kolobashkin A.V., \\ ${ }^{1}$ Koritz S.I., ${ }^{1}$ Bokova I.B., ${ }^{2}$ Chichin S.V. \\ ${ }^{1}$ Federal State State Educational Institution of Higher Education Omsk Academy of the Ministry \\ of internal Affairs of the Russian Federation, Omsk, e-mail:oma@mvd.ru; \\ ${ }^{2}$ Branch of the Federal State Military Educational Institution Higher Education VA MTO \\ im. General of the army A.V. Khrulev, Omsk, e-mail: otiu@mil.ru
}

\begin{abstract}
The article is devoted to the review of developments in the field of means of forced stopping of transport. The relevance of the topic is due to the increased degree of danger created during the pursuit of the offender's vehicle. Among the wide variety of methods used to stop vehicles, there are still a number of disadvantages that affect the effectiveness of the stopping process. Some of the used means of forced stopping of transport, which are in service with the internal Affairs bodies, are morally and physically outdated, which, of course, requires special attention and approach to this problem. Based on the review, a classification of means of forced stopping of transport by type of basing, the type of devices used, the nature and methods of influence on the stopped vehicle is proposed. The authors note that in addition to the armed forces of the internal Affairs bodies of the Russian Federation means of forced stopping of transport, the principle of which is based on puncturing the tires of the pursued vehicles, there is a fairly large volume of devices based on new principles. The developments considered in the scientific review can complement the functional features of existing ones, increasing the overall efficiency of the process of stopping the offender's vehicle, and replace them, presenting a worthy alternative. As a result of the research, the authors made proposals to improve the effectiveness of the use of means of forced transport stopping, to equip the territorial bodies of internal Affairs with appropriate devices, to monitor and diagnose the quality of production and use of these means.
\end{abstract}

Keywords: scientific review, forced stop, means of forced stop of transport, classification, suggestions, efficiency improvements, control

Проблема выполнения остановки транспортного средства, водитель которого отказывается выполнить законные требования сотрудника полиции, и по сей день является во всех отношениях весьма острой, требу- ющей системного подхода в части выбора способа остановки транспортного средства при безусловном обеспечении безопасности лиц, принимающих участие в дорожном движении. К способам, применяемым 
для принудительной остановки транспорта, относятся размещение на проезжей части специальных переносных устройств («ЕЖ», «Диана» и т.д.) и стационарных устройств на постах ДПС; блокирование патрульными автомобилями и автомобилями, принадлежащими гражданам; размещение на проезжей части подручных средств; применение огнестрельного оружия [1].

Статистика применения способа принудительной остановки транспортного средства путем контактного взаимодействия с транспортным средством нарушителя, двигающимся на большой скорости, свидетельствует о высокой степени травматизма участников дорожного движения в результате преследования [2]. Применение огнестрельного оружия для остановки транспортного средства нарушителя, представляющего опасность для окружающих водителей, пассажиров и пешеходов, является наиболее опасным и рискованным способом, о чем свидетельствует большое количество резонансных случаев, при которых вместо движущей части автомобиля пули поражали лиц, находящихся в транспортном средстве. Кроме того, практика использования огнестрельного оружия для принудительной остановки транспорта свидетельствует о сложности его эффективного применения - число попаданий по ходовой части автомобиля не превышает $10 \%$ [3].

Известные устройства принудительной остановки транспорта, состоящие на вооружении органов внутренних дел Российской Федерации [4], имеют ряд недостатков, которые могут ограничивать их применение в зависимости от типа и конфигурации дорожного покрытия, времени приведения их в готовность (вес, сложность устройства и необходимость приведения в готовность двумя и более сотрудниками), могут повлечь потерю управления автомобилем, эффективность применения (в ряде случаев автомобиль продолжает движение).

Цель исследования: выполнение научного обзора разработок в области средств принудительной остановки транспорта для выявления современных методов и способов реализации принудительной остановки транспорта с учетом особенностей их применения в различных условиях, а также разработка классификации средств принудительной остановки транспорта, способствующей реализации их выбора в зависимости от вида базирования, типа, характера и способа воздействия на останавливаемое транспортное средство с внесением предложений по повышению эффективности использования указанных средств.

\section{Материалы и методы исследования}

Материалом исследования послужили научные статьи и пособия в области обеспечения личной безопасности сотрудниками органов внутренних дел, патенты на полезные модели и изобретения по направлению реализации принудительной остановки транспорта.

В качестве методов исследования применялись следующие: методы анализа, абстрагирования, индукции и дедукции, аналогии, системный подход.

\section{Результаты исследования и их обсуждение}

В ходе проведения научного обзора авторами выполнена классификация известных средств принудительной остановки транспорта по следующим признакам: видам базирования, типам применяемых устройств, характеру и способам воздействия на преследуемое транспортное средство.

Наиболее простой и наглядной классификацией является распределение средств принудительной остановки транспорта по видам базирования (рис. 1).

Детально рассмотрим составляющие классификации средств принудительной остановки транспорта по видам базирования. При этом во внимание будем принимать средства принудительной остановки транспорта, отличные от применяемых в органах внутренних дел Российской Федерации.

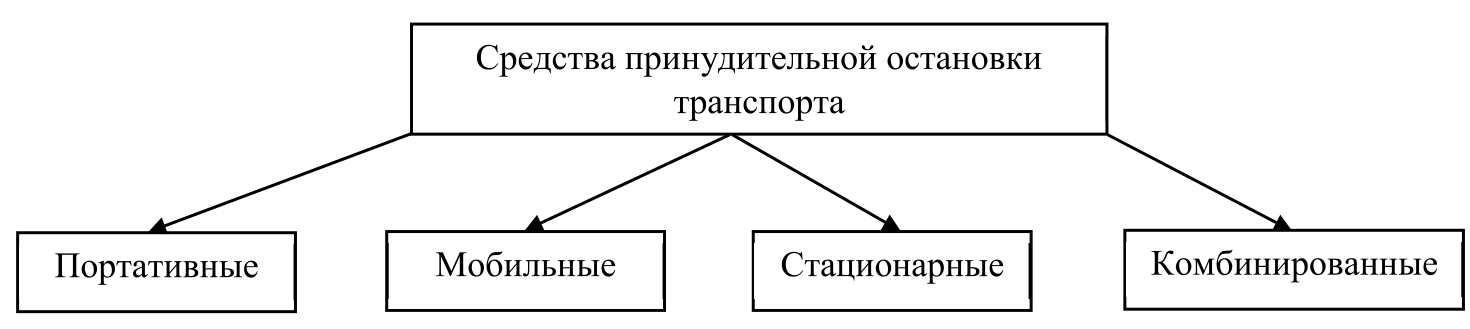

Рис. 1. Классификация средств принудительной остановки транспорта по видам базирования 
TECHNICAL SCIENCES (05.02.02, 05.02.04, 05.02.07, 05.02.09, 05.02.10, 05.02.11,

\section{Портативные средства принудительной остановки транспорта}

Общая особенность подобных устройств заключается в наличии шипов, расположенных вертикально или под определенным углом. Так, одно из устройств для удобства его перемещения выполнено из гибкого материала [5], в сложенном состоянии представляет собой рулон по аналогии с известными средствами принудительной остановки транспорта, например «Лиана 6000» [4], имеет прокалывающие элементы и обеспечивает обязательную, хотя и не мгновенную, остановку транспортного средства. Отличие заключается в дополнительном блокировании пары колес по ходу движения автомобиля. Другое устройство по аналогии с вышеперечисленными также обеспечивает прокалывание шипами колес транспортного средства [6], однако конструктивно выполнено по схеме пантографа, что обеспечивает компактность конструкции, а также быстродействие устройства при приведении в рабочее состояние. Указанные устройства имеют очень важное свойство - работоспособность в условиях асфальтового и грунтового покрытия дорожного полотна. Подобные устройства для принудительной остановки транспорта могут иметь аналогичную конструкцию, размещаться поперек дорожной полосы, выполняться по другим схемам, например в виде параллелограмма [7] или в виде цепи или ленты с закрепленными шипами [8, 9], и предусматривают последующую доработку с целью автоматизации процесса установки [10]. Интересным может быть применение в качестве портативного средства принудительной остановки транспортного средства изобретения [11], хотя и предназначенного для собственной безопасности водителя и пассажиров транспортного средства, на котором это устройство установлено, однако, по нашему мнению, идея очень интересная, и отдельно или в совокупности с вышеперечисленными устройствами оно могло бы повысить эффективность и безопасность процесса остановки.

\section{Мобильные средства принудительной остановки транспорта}

Общими особенностями мобильных устройств являются возможность их перемещения совместно с преследующим патрульным автомобилем и дистанционное воздействие на автомобиль, который должен быть подвергнут принудительной остановке. Особое место в этих системах занимает механическое устройство принудительной остановки транспортного сред- ства, представляющее собой гибкий трос с двумя метательными грузами для захвата заднего колеса и его блокирования, либо имеющий множество сегментов, шарнирно связанных с расположенными между грузами шипами [12].

Большинство мобильных устройств выполнено по принципу электромеханического или электромагнитного воздействия на транспортное средство правонарушителя. Так, одно из устройств электромеханического воздействия основано на производстве выстрела элемента, например арбалетом [13], с целью размещения и закрепления на преследуемом транспортном средстве и обеспечения электрической связи источника и приемника (автомобиля) с последующим воздействием на систему зажигания транспортного средства. Другое устройство воздействует на топливную систему, в которой расположен приемник, назначение которого - получение сигнала от устройства, находящегося в патрульном автомобиле [14]. Аналогичны по принципу работы «генератор - приемник» устройства, основанные на приведении в рабочее состояние тормозной системы и связанной с ней системы курсовой устойчивости [15], и следящие системы c GSM-приемопередатчиками, связанными с блоком управления системой транспортного средства [16].

\section{Стационарные средства принудительной остановки транспорта}

К таким устройствам могут быть отнесены различные ворота, шлагбаумы, балки с вмонтированными в основания прокалывающими и режущими элементами, тросовые устройства, системы-ловушки и т.д. В качестве примера ворот, используемых для принудительной остановки транспортного средства без существенного повреждения в случае попытки несанкционированного доступа на охраняемую территорию, стоит привести устройство [17], которое с помощью датчиков дистанционно определяет скорость и вес транспортного средства с целью контроля усилия, воздействующего на останавливаемое транспортное средство. Устройство, указанное в [18], также действует без существенного повреждения транспортного средства с учетом блокирования движения в направлении охраняемой территории в совокупности с эффектом отбрасывания транспортного средства в противоположном направлении за счет демпфирующих элементов. По аналогии с портативными устройствами, которые обеспечивают прокалывание шин транспортного средства, выполнена установ- 
ка, вмонтированная в бетонное основание с расположенным на валу зубцом в форме сапожка [19]; без эффекта прокалывания шин выполнено устройство, описанное в $[20,21]$. К устройствам, обеспечивающим значительную деформацию транспортного средства при столкновении с ними, относятся заградительные элементы, например c шипами, позволяющими прокалывать шины с одновременным эффектом блокирования движения транспортного средства в попутном направлении [22], или без шипов, выполненные по принципу барьеров шлагбаумного типа [23, 24]. Достаточно интересным является решение по применению заранее подготовленной водонепроницаемой емкости с дисперсным материалом, при необходимости принудительной остановки транспорта взаимодействующим с системой, обеспечивающей подачу воды [25]. В заключение стоит привести устройство, выполненное по типу «шипованный лежачий полицейский» [26], приводимое в рабочее состояние дистанционно: сигнал, поступающий на устройство, по- зволяет привести в работу шипы, выступающие на искусственной неровности.

Комбинированные средства принудительной остановки транспорта

К таким устройствам относятся мобильные шлагбаумы, которые обеспечивают блокирование движения транспортных средств в определенных направлениях и в отличие от стационарных устройств имеют возможность быстрого монтажа на участке регулирования или контроля движения [27].

Таким образом, проведенный обзор средств принудительной остановки транспорта по видам базирования позволяет разработать классификацию средств по типу применяемых устройств для остановки транспортных средств (рис. 2).

При рассмотрении условий базирования транспортных средств и типов применяемых устройств для остановки транспортных средств необходимо акцентировать внимание на классификации устройств по характеру и способам воздействия на останавливаемое транспортное средство (рис. 3 ).

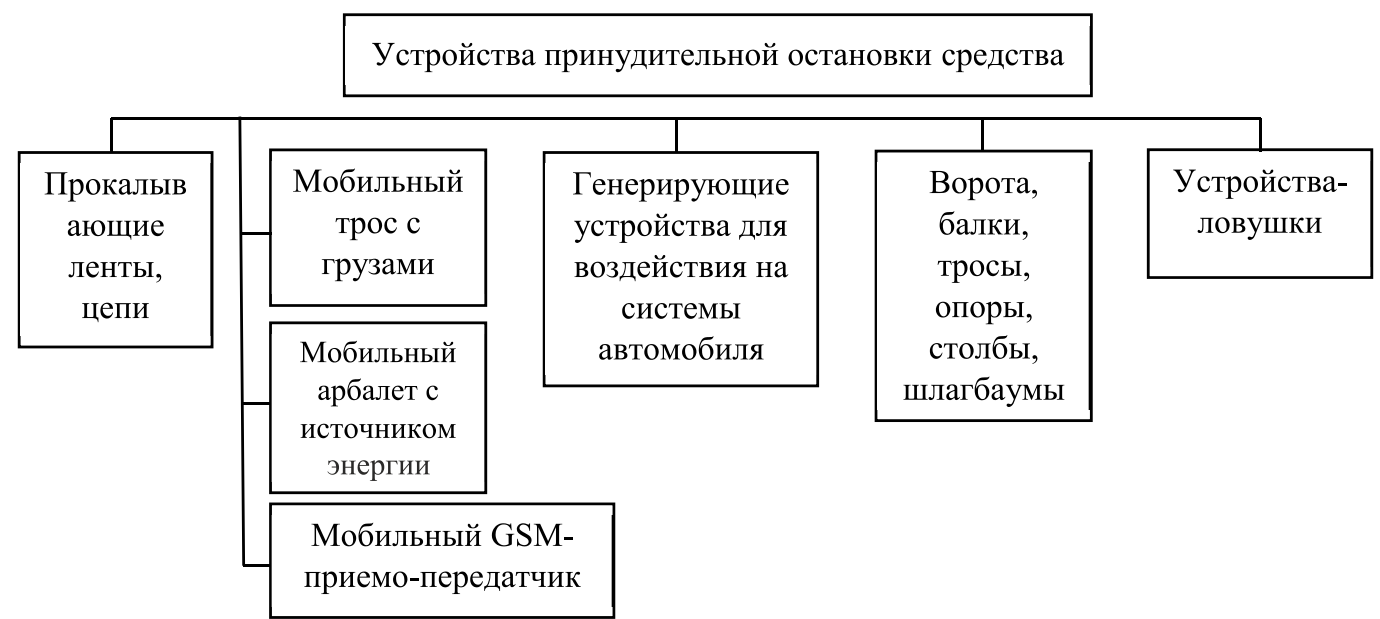

Рис. 2. Классификащия средств принудительной остановки транспорта по типу применяемых устройств для остановки транспортных средств

Средства принудительной остановки транспорта

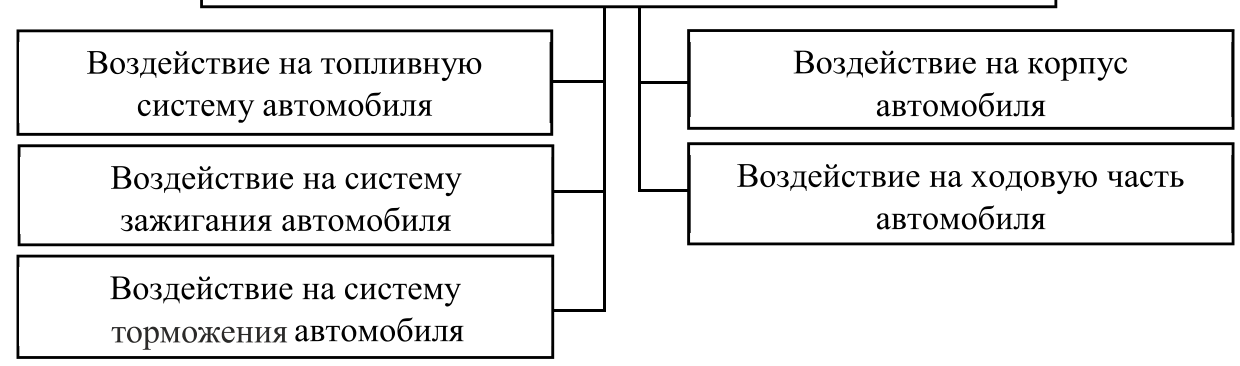

Рис. 3. Классификация устройств принудительной остановки транспорта по характеру и способам воздействия на останавливаемое транспортное средство 
TECHNICAL SCIENCES (05.02.02, 05.02.04, 05.02.07, 05.02.09, 05.02.10, 05.02.11,

\section{Зарубежные средства принудительной} остановки транспорта

Анализ зарубежных разработок в области средств принудительной остановки транспорта показал, что проблеме повышения эффективности остановки преследуемого транспортного средства уделяется достаточно большое внимание. Стоит отметить, что приведенные в настоящей работе классификации средств принудительной остановки транспорта справедливы и для зарубежных разработок. При этом акцент при разработке портативных средств принудительной остановки транспорта сделан в пользу устройств, обеспечивающих мгновенность остановки, минимальный ущерб останавливаемому транспортному средству, компактность, надежность и простоту контроля работоспособности $[28,29]$. В качестве примера приведем одно из мобильных устройств, представленных в источнике [30]: принцип работы устройства основан на блокировании заднего колес (колес) преследуемого транспортного средства с помощью тросового устройства, закрепленного на патрульном автомобиле. Достаточно много зарубежных разработок запатентовано в области позиционирования и прогнозирования местоположения преследуемого транспортного средства, один из примеров описан в [31].

В результате проведенного научного обзора авторами настоящей статьи предлагается следующее.

1. Комплектование автомобилями, оборудованными мобильными устройствами для принудительной остановки транспорта, и обучение личного состава применению указанных устройств.

2. Разработка методики определения требуемого количества патрульных автомобилей, оборудованных мобильными устройствами для принудительной остановки транспортных средств, в зависимости от статистических данных по преследуемым транспортным средствам, протяженности территории населенного пункта, количества жителей и т.д.

3. Размещение скрытых стационарных устройств для принудительной остановки транспорта. Применение комбинации способов остановки преследуемого транспортного средства должно способствовать повышению эффективности данного процесса.

4. Усиление разработок по определению местоположения преследуемого транспортного средства с возможностью привязки к городской системе управления светофорной сигнализации (при наличии).
5. Контроль, диагностика и поддержание работоспособности устройств для принудительной остановки транспорта на всех этапах - от производства до фактического применения [32, 33].

\section{Заключение}

Разнообразие модификаций средств принудительной остановки транспорта представлено устройствами, принцип работы которых основан на эффекте прокалывания транспортных шин, их достоинства, недостатки и основные разработки рассматривались ранее. Мобильные тросы с грузами, арбалеты с источниками энергии, мобильные GSM-приемопередатчики позволяют осуществить практически мгновенную остановку преследуемого транспортного средства, в отличие от устройств, основанных на эффекте прокалывания транспортных шин. Однако для успешной реализации указанных средств необходимо создание целого ряда условий, таких как: обеспечение высокой надежности и безотказности устройств, надежность размещения на транспортных средствах, высокий профессионализм водителя, управляющего автомобилем, оснащенным устройством для принудительной остановки транспорта, а также навыки применения таких средств. Устройства-ловушки могут быть эффективны при их достаточно быстрой установке, надежности срабатывания; в случае размещения их в стационарном режиме необходимо обеспечивать их скрытую установку, возможность дистанционного контроля за их техническим состоянием. Генерирующие установки, воздействуя на системы автомобиля, могут обеспечивать наряду с мобильными устройствами других видов достаточно быструю и эффективную остановку транспортного средства без его разрушения и потери управления, однако для реализации принудительной остановки таким способом потребуется дооснащение необходимыми электронными приемниками транспортных средств граждан, что может вызвать трудности при реализации такого способа.

Подводя итог вышесказанному, стоит отметить, что предложения, выдвинутые авторами, основываются на опыте сотрудников правоохранительных органов, действовавших в условиях преследования транспортных средств и применения средств принудительной остановки транспорта. Не вызывает сомнения, что тема остается актуальной и останется такой на долгие годы в связи с развитием технологий не только в правоохранительных органах, но и в криминальных кругах. 
ТЕХНИЧЕСКИЕ НАУКИ (05.02.02, 05.02.04, 05.02.07, 05.02.09, 05.02.10, 05.02.11, $05.02 .13,05.02 .18,05.02 .22,05.13 .06,05.13 .10,05.13 .11,05.13 .17,05.13 .18)$

\section{Список литературы}

1. Тактика действий сотрудников ОВД по задержанию преступников, передвигающихся на автотранспорте: учебное пособие / сост. Д.Б. Кавецкий, А.А. Каримов, А.А. Сысоев. Иркутск: ФГКОУ ВПО ВСИ МВД России, 2015. 48 с.

2. Хакимзянов А.Р. Проблемы обеспечения мер личной безопасности при несении службы сотрудниками Госавтоинспекции // Вестник НЦБЖД. 2017. № 4 (34). С. 112-120.

3. Басатин А.Е. Особенности действий по задержанию вооруженных преступников, передвигающихся на автомобиле// Научный вестник Орловского юридического института МВД России имени В.В. Лукьянова. 2017. № 4 (73). С. 104-106.

4. Кныш В.П., Синева А.Р., Горькушев А.Ю. Мобильные системы принудительной остановки автотранспорта // Вопросы оборонной техники. Серия 16: Технические средства противодействия терроризму. 2014. № 9-10 (75-76) C. $135-140$.

5. Манылов О.А. Устройство для принудительной остановки транспортных средств // Патент РФ №153738. Патентообладатель Манылов О.А. 2015. Бюл. № 21.

6. Туккаев П.К. Устройство для принудительной остановки автотранспорта // Патент РФ №2554619. Патентообладатель Туккаев П.К. 2015. Бюл. № 18.

7. Сильников М.В., Сильников Н.М., Панков А.С., Иванов С.Е. Заграждение для автотранспорта // Патент РФ №2677731. Патентообладатель Закрытое акционерное общество «Научно-производственное объединение специальных материалов» (ЗАО «НПО СМ»). 2019. Бюл. № 3.

8. Бездольный Н.И. Устройство для принудительной остановки транспортного средства // Патент РФ №2027824. Патентообладатель Бездольный Н.И. 1995.

9. Зазульский А.А., Дзюба Н.Я., Котенев А.Ю., Капустин Н.А., Сазонов П.Ф., Волков А.С. Устройство для принудительной остановки транспортных средств на пневматических шинах // А.c. 1390289 СССР, МПК Е 01 М 13/00. № 4105974/40-11, заявлено 11.05.86; опубл. 23.04.88; Бюл. № 15. С. 2

10. Самохвалов В.А. Заградитель для автомототранспорта // Патент РФ № 2101659. Патентообладатель Самохвалов В.А. 1998.

11. Юскаев Ю.Ю. Устройство принудительной остановки автомобиля // Патент РФ № 2657160. Патентообладатель Федеральное государственное бюджетное образовательное учреждение высшего образования «Уральский государственный лесотехнический университет». 2018. Бюл. № 16.

12. Кристл Я.-Мэй, Гудман Майкл К. Средство захвата для останова преследуемого автомобиля (варианты) и способ спускания задней шины // Патент РФ №2420625. Патентообладатель Кристл Я.-Мэй, Гудман Майкл К. 2011. Бюл. № 16.

13. Таланов Б.П. Способ принудительной остановки транспортного средства // Патент РФ № 2110749. Патентообладатель Таланов Б.П. 1998.

14. Лутов В.Н. Блокирующее устройство в транспортном средстве // Патент РФ № 102569. Патентообладатель Лутов В.Н. 2011. Бюл. № 7.

15. Шереметьев Д.В. Система принудительного управления транспортным средством // Патент РФ № 187287. Патентообладатель Шереметьев Д.В. 2019. Бюл. № 7.

16. Куликов Е.А. Система дистанционной остановки транспортных средств // Патент РФ № 2657143. Патентообладатель Куликов Е.А. 2018. Бюл. № 16.

17. Васильев И.В., Гуськов В.Д., Долбенков В.Г., Зайцев Б.И., Лямин К.А., Чуркин К.Н. Способ принудительной остановки транспортного средства при проезде на охраня емую территорию // Патент РФ № 2407853. Патентообладатель Открытое акционерное общество «Конструкторское бюро специального машиностроения». 2010. Бюл. № 36.
18. Точилин О.Н., Дворецкий С.А., Зайцев Ю.В., Козлов Н.Е. Заградительное устройство // Патент РФ № 2465392. Патентообладатель Федеральное государственное учреждение «12 Центральный научно-исследовательский институт Министерства обороны Российской Федерации». 2012. Бюл. № 30 .

19. Половиткин А.Ю., Гестрин Б.И., Гестрин В.Б. Устройство для принудительной остановки колесного транспортного средства // Патент РФ № 2141550. Патентообладатель Половиткин А.Ю., Гестрин Б.И., Гестрин В.Б. 1999.

20. Валиуллин А.М.Врезной в дорожное полотно противотаранный дорожный блокиратор // Патент РФ № 194993. Патентообладатель Общество с ограниченной ответственностью «ПермЭнергоМаш». 2020. Бюл. № 1.

21. Тарасов Д.А., Большаков Г.С., Васильев И.В., Шаповал О.Л. Противотаранное заграждение // Патент РФ № 191852. Патентообладатель Закрытое акционерное общество «Центр специальных инженерных сооружений научноисследовательского и конструкторского института радиоэлектронной техники» (ЗАО «ЦеСИС НИКИРЭТ»). 2019. Бюл. № 24 .

22. Беляев В.В., Болдырев А.П., Гейко О.В., Шумаков И.В. Средство принудительной остановки автомобильного транспорта // Патент РФ № 87007. Патентообладатель Открытое акционерное общество «Конструкторское бюро транспортного машиностроения». 2009. Бюл. № 26.

23. Сильников М.В., Мельников И.А., Бровкин А.В., Панков А.С. Барьер противотаранный шлагбаумного типа // Патент РФ № 2677730. Патентообладатель Закрытое акционерное общество «Научно-производственное объединение специальных материалов» (ЗАО «НПО СМ»). 2019. Бюл. № 3 .

24. Белый Д.М., Овсянникова Н.Б., Петрова Т.Е. Шлагбаум // Патент РФ № 129518. Патентообладатель Федеральное государственное бюджетное образовательное учреждение высшего профессионального образования «Ульяновский государственный технический университет». 2013. Бюл. № 18 .

25. Касьянов А.Е. Устройство для принудительной остановки транспортного средства // Патент РФ № 2229552. Патентообладатель Касьянов А.Е. 2004. Бюл. № 15.

26. Рудич Е.Н., Игнатов Ю.В. Устройство для принудительной остановки или ограничения скорости транспортного средства // Патент РФ № 52870. Патентообладатель Рудич Е.Н., Игнатов Ю.В. 2006. Бюл. № 12.

27. Кожевников А.В. Шлагбаум противотаранный мобильный // Патент РФ № 167964. Патентообладатель Кожевников А.В. 2017. Бюл. № 2.

28. Izutani Toru. Vehicle forced stopping device. International Application No. PCT/JP2018/017111. Applicants Izutani Toru. 2018.

29. Imamura Akihiko, Kawaguchi Hirotsugu, Fukazawa Tatsuya. Vehicle forced stopping device. Application Number 2018030270. Applicants Imamura Akihiko. 2019.

30. Stock Jr. Leonard Charles. Vehicle arresting apparatus. Application Number 12263599. Applicants Stock Jr. Leonard Charles. 2010

31. Tang Bin, Yang Leng. Chase after car system based on GPS location. Application Number 2018030270. Applicants Beijing chexiao technology C., Ltd. 2018.

32. Tugengol'd A.K., Dimitrov V.P., Borisova L.V., Grankov M.V., Voloshin R.N. Autonomous maintenance of digital equipment. Russian engineering research. 2019. № 6. P. 510515. DOI: 10.3103/S1068798X19060194.

33. Kholopov V.A., Kashirskaya E.N., Shmeleva A.G., Kurnasov E.V. An intelligent monitoring system for execution of machine engineering processes. Journal of machinery manufacture and reliability. 2019. № 5. P. 464-475. DOI: 10.3103/ S1052618819020079. 